\title{
Study on Fracturing Technology of Polymer Flooding in the Second
}

\section{Class Reservoir}

\author{
Hui Xing \\ The third oil production plant, Daqing Oilfield Company Ltd, Daqing,163412,China \\ Xinghui831203@126.com
}

Key words: The Second Type Reservoir; Fracturing Timing; Selection of Wells and Layer

\begin{abstract}
The length, number of layers, plane and longitudinal heterogeneity of injection wells of the second class reservoir are serious. The fractures are used to relieve the contradiction between the plane and the strata, and the channel edge and get the remaining oil potential difference between site type. In this paper, the parameters related to fracturing are studied, such as the decline of fluid production, the decrease of water cut and the connectivity of river channel. The pressure of polymer flooding stage is determined by the combination of fine reservoir description and logging and well test data. The principle of choosing wells and selecting layers in fracturing wells at each stage of polymer flooding is summed up. After practice, the effect of increasing oil and precipitation is obtained, and an effective way is found for the efficiency of polymer flooding.
\end{abstract}

\section{Introduction}

With the development of polymer flooding in the second type reservoir, the influence of the interlayer and the plane contradiction on the polymer flooding effect of the second class reservoir is becoming more and more serious. Some problems can be solved effectively by the fracturing of the oil production well, but how to effectively improve the oil well fracturing effect, And further improve the efficiency of polymer flooding in the second class reservoirs. Therefore, the problems such as the timing of fracturing, the principle of selection of well selection layer and so on in the polymer flooding stage need further study.

\section{Fracturing Time}

Through the numerical simulation and field effect analysis, it is concluded that the main reservoir fracturing in polymer flooding production well should be carried out with the water cut and water cutoff period. The effect of water recovery period is obviously worse. At this time, the thin oil layers should be fractured, To change the low permeability reservoir seepage conditions, in order to improve the degree of its use[1-2].

The results of numerical simulation show that the recovery range of fracturing oil recovery is $0.94 \%$ in water cut stage and $0.96 \%$ in low water cut, respectively, while that of fracturing oil recovery is $0.96 \%$ in low water cut. The recovery of the thin and poor reservoir in the water recovery stage can improve the recovery rate by $0.56 \%$, and the recovery rate is higher than that of the main reservoir by fracturing (Table 1$)$. 
TABLE 1. The results of numerical simulation of the fracturing in the different stage of polymer flooding

\begin{tabular}{|c|c|c|c|c|}
\hline \multirow{2}{*}{ Period. } & Layer & $\begin{array}{c}\text { Increased Amount of oil } \\
\left(10^{4} \mathrm{t}\right)\end{array}$ & $\begin{array}{c}\text { Fracturing Amount of Oil } \\
\left(10^{4} \mathrm{t}\right)\end{array}$ & Eor(\%) \\
\hline \multirow{2}{*}{ Water Cut } & Major Layer & 3.395 & 0.243 & 0.94 \\
\cline { 2 - 5 } & Thin Layer & 3.235 & 0.083 & 0.33 \\
\hline \multirow{2}{*}{ Water Cutoff } & Major Layer & 3.390 & 0.238 & 0.96 \\
\cline { 2 - 5 } & Thin Layer & 3.250 & 0.098 & 0.39 \\
\hline \multirow{2}{*}{ Water Recovery } & Major Layer & 3.175 & 0.023 & 0.09 \\
\cline { 2 - 5 } & Thin Layer & 3.295 & 0.143 & 0.56 \\
\hline
\end{tabular}

According to the change of water content in the different stages of polymer flooding in the two types of reservoirs, the measures of fracturing in water cut and low water content are more effective than the earlier period and the water recovery period, and the water cut decreases greatly The results also show that the effect of polymer flooding oil well is closely related to the water cut stage after polymer flooding[3-5]. In the water drop and the lower stage fracturing effect; while in the water recovery rate decreases, especially in the mid and late period should not take this period of oil well fracturing, fracturing the amount of recovery, will lead to the rise of water cut.

\section{Selection of fracturing wells}

\section{Selection of Fracturing Wells}

First, wells with high oil saturation and good physical properties are preferred. As the material foundation, whether the target well accumulates the remaining oil is directly related to the fracturing effect. Fig. 1 shows the scatter plot of oil saturation and daily oil increment of the fracturing wells . It can be seen that with the increase of oil saturation, the daily increasing oil has a tendency to increase[6-7]. Through the statistical analysis, it is found that the permeability is between $0.2-0.4 \mu \mathrm{m} 2$ and the oil saturation is more than $48 \%$, so the reservoir fracturing effect is good; the permeability is poor and the formation coefficient is small, and it is difficult to add enough sand even in fracturing construction The formation of effective diversion cracks. However, fracturing is not ideal because the formation factor is too large. The reason is that the well with large formation factor is too large, the permeability is relatively large, the flooding is serious and the oil saturation is low.

The Growing Amount of Oil(t/d)

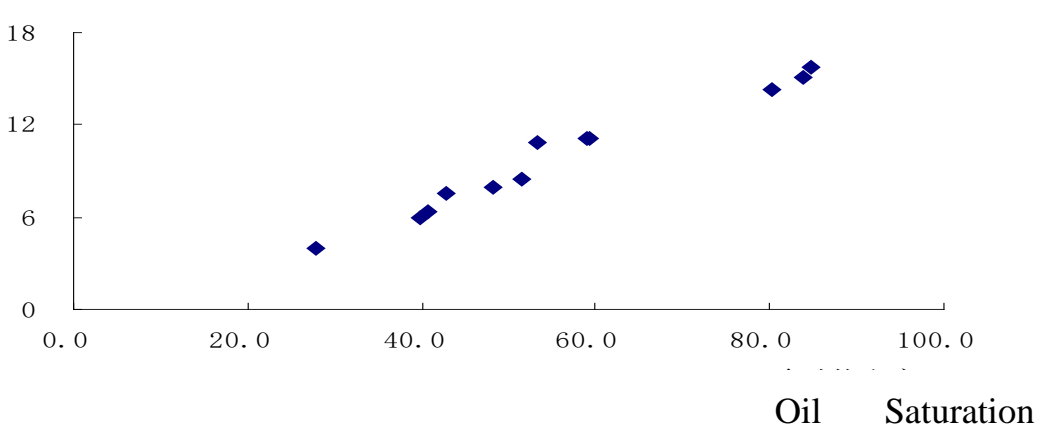

Figure 1. The scatter plot of oil saturation and daily oil increment of the fracturing wells

The second is to optimize the amount of fluid production, decline in water content, the cumulative increase in oil wells. The results show that the fracturing effect of oil well is better when 
the water cutoff period is less than $30 \%$, and the decrease of fluid production is greater than that of water recovery period $10 \%$ of oil production wells are suitable for fracturing. In the effective period, fracturing effect of oil production wells with water cut of more than $20 \%$ is better than that of effective recovery period, and the recovery period is the potential tapping potential; The less the fracturing effect is.

Third, logging, well testing data has the potential of fracturing wells. (1) the skin coefficient of the well: the skin coefficient is used to characterize a well near the bottom of the perfect degree, select the skin coefficient of the well, that is, low well completion of well fracturing, can effectively improve the near well zone seepage conditions, To obtain a better fracturing effect. From 17 wells in the well test data of the five wells statistics, the pressure before the skin coefficient, the greater the amount of oil after the pressure increase. (2) the coefficient of flow of small wells: skin coefficient of the bottom of the characterization of the degree of perfection, can not reflect the loss of energy wells, production capacity. Flow coefficient can be directly given the wall resistance coefficient on the impact of production capacity. The results show that the increasing oil flow rate increases with the decrease of the flow coefficient before pressing, the smaller the flow coefficient before pressing, and the bigger the daily increasing oil after pressing. (3) In the fractured wells, it is preferable to use well logging data, and the wells with potential utilization of low level and low water content are better. For example, the A well, before and after the fracturing of the fluid production profile can be seen before the use of fracturing layer thickness ratio of only $15.6 \%$ relative to the liquid yield of $23.8 \%$, after the use of the thickness ratio of $36.9 \%$ The relative yield of 49.5\%; for no output profile, we can connect injection wells through the injection profile to determine the analysis of the use of oil production wells, such as B well, the well is not measured output profile, by means of According to the analysis of injection-production relationship, the strong water absorption layer of injection well is the main production layer of the production well, and the high aquifer is the main water-producing layer of the well. The numerical simulation shows that the remaining oil is enriched in the horizon of poor use, and finally the well is fractured well.

2.Selection of Fracturing Layers.

First, it is preferred to have a low water content and low flooding interval. Through analysis, the choice of low water and flooded, remaining oil relative to the enrichment of fracturing layers, is conducive to the wells after fracturing water cut down, oil production increased significantly. The results show that the effect of fracturing and oil production is obvious when the proportion of high water flooding is less than $40 \%$. Note that it is necessary to clarify the current remaining oil distribution when the fracturing interval is preferred during the water recovery period. Once the high water flooding zone is pressed, the water content will rise rapidly and reduce the water recovery period to a certain extent Of the recovery, affecting the overall effect of polymer flooding.

The second is to optimize the injection and production, river sand connectivity layer thickness ratio. From the results of fine reservoir description, the target layer of fracturing should have a high degree of polymer flooding control, a class of connectivity ratio to be more than $70 \%$, the production wells for each fracturing of the target layer are at least two directions and above Of the injection well is a kind of connectivity. The results show that the wells with more than $60 \%$ polymer flooding control pressure can be effective wells, the daily increasing oil is more than $5 t$, the degree of polymer flood control is more than $65 \%$, and the daily increasing oil can reach more than 10t. It can be seen from the relationship curve between the degree of polymer flooding and the daily increase of oil pressure. The daily increasing oil increases with the degree of polymer flooding control. The results show that the greater the proportion of channel sand is, the better the oil production is, the more oil increases after fracturing, the better the ratio of the increasing oil content 
to the ratio of channel sand to the ratio of channel sand before and after fracturing. The ratio of the thickness of the sand channel is more than $50 \%$, and the fractures are all effective wells. The ratio of the channel sand is more than $83 \%$, and the fracturing is the high efficiency well .

Third, according to the different stages of fracturing preferred type and measures the thickness of layer. Combining the features of oil production well and the characteristics of remaining oil distribution, the types of fracturing horizons in each stage are determined. Water cut down: the edge of the river and the reservoir variation; low water period: the main body parts of the river; water recovery period: Delta front delta-based thin difference layer.

It is found that fracturing well at all stages of the second type of reservoir can be found to be effective after fracturing (increasing oil by more than $5 \mathrm{t}$ ). There are certain requirements for the thickness of the fracturing layer: when the water content is less than $80 \%$, the thickness should be greater than $4 \mathrm{~m}$; $80 \%-90 \%$, measure the thickness of more than $5 \mathrm{~m}$; water is greater than $90 \%$, the measure thickness is greater than $6 \mathrm{~m}$.

\section{Choice of fracturing methods}

Ordinary Fracturing: fracturing layer with low water content, interlayer condition is good, can constitute a fracturing section alone, the general use of ordinary fracturing technology, the way for the water cut down the edge of the river channel, low fluid production, the remaining oil rich Set of oil production wells.

Selective Fracturing: Selective fracturing techniques can be used for wells with large reservoir thickness, non-uniform flooding within the strata, or multi-layer compression with high aquifers. This method is applied to the oil production well with large decrease of the fluid production rate in combination with the common fracturing.

Multi-fracture Fracturing: fracturing layer, thin layer, can not single-card layer can be multi-fracture fracturing, the way for the water recovery phase of thin layer development, multi-directional connectivity, high concentration of poly Production wells.

\section{Conclusion}

(1) The best fracturing period of polymer flooding stage is the low water cut stage;

(2) fracturing layer thickness, flooding degree, connectivity is an important guarantee of fracturing effect.

(3) Fracturing horizon is preferred, and the optimal fracturing mode is the key.

\section{References}

[1]. Xu Jianjun, Xu Yan-chao, Yan, Li-me,et.al. Research on the method of optimal PMU placement. International Journal of Online Engineering,v9, S7, p24-29, 2013

[2]. Xu Jian-Jun, Y. Y. Zi., Numerical Modeling for Enhancement of Oil Recovery via Direct Current. International Journal of Applied Mathematics and Statistics, 2013, 43 (13) : 318-326

[3]. Longchao, Zhu Jianjun, Xu; Limei, Yan. Research on congestion elimination method of circuit overload and transmission congestion in the internet of things. Multimedia Tools and Applications, p 1-20, June 27, 2016

[4]. Yan Limei, Zhu Yusong, Xu Jianjun,et.al. Transmission Lines Modeling Method Based on Fractional Order Calculus Theory. TRANSACTIONS OF CHINA ELECTROTECHNICAL SOCIETY, 2014 ,Vol.29,No. 9:260-268 (In Chinese) 
[5]. YAN Li-mei, CUI Jia, XU Jian-jun,et.al. Power system state estimation of quadrature Kalman filter based on PMU/SCADA measurements. Electric Machines and Control. 2014, Vol.18 No.6,: 78-84. (In Chinese)

[6]. YAN Limei,XIE Yibing, XU Jianjun, et.al. Improved Forward and Backward Substitution in Calculation of Power Distribution Network with Distributed Generation. JOURNAL OF XI'AN JIAOTONG UNIVERSITY,2013, Vol.47, No.6, p117-123. (In Chinese)

[7]. Xu J.J., Gai D., Yan L.M. A NEW FAULT IDENTIFICATION AND DIAGNOSIS ON PUMP VALVES OF MEDICAL RECIPROCATING PUMPS. Basic \& Clinical Pharmacology \& Toxicology, 2016,118 (Suppl. 1), 38-38 